\title{
The factor structure of the Normative Beliefs about Aggression Scale as used with a sample of adolescents in low socio-economic areas of South Africa
}

\author{
Anita Padmanabhanunni
}

\begin{abstract}
The issue of adolescent aggression and violence has received significant attention in the literature. Normative beliefs about the acceptability of aggressive behaviour have been identified as central in influencing aggression. The Normative Beliefs about Aggression Scale was developed to identify cognitive beliefs about the acceptability of aggressive behaviour. The scale has been extensively used in research on child and adolescent aggression and has consistently demonstrated that normative beliefs account for variances in adolescent aggressive behaviour, predict aggression, and mediate the relationship between risk factors and aggression among this population group. Despite extensive use of this scale in other contexts, information is lacking on its psychometric properties. A full analysis of the factor structure of the Normative Beliefs about Aggression Scale has not yet been conducted. This study presents the first test of the factor structure of the full instrument and confirms that the Normative Beliefs about Aggression Scale is a reliable instrument when used in the South African context. The results point to the multidimensional nature of beliefs about aggression and provide an important foundation for future research into correlates of aggressive behaviour in different cultural contexts.
\end{abstract}

The issue of adolescent aggression and violence has received significant attention in the literature. In South Africa, various studies on youth risk behaviour have demonstrated the prevalence of bullying (Boyes, Bowes, Cluver, Ward, \& Badcock, 2014; Liang, Flisher \& Lombard, 2007), intimate partner violence (Russell et al., 2014), sexual assault (Jewkes, Flood, \& Lang, 2015), and homicide (Swart, Seedat, \& Nel, 2015) among this population group. The propensity to engage in aggressive behaviour has been demonstrated to be the outcome of the interaction of individual (e.g., locus of control, self-esteem: Wallace, Barry, Zeigler-Hill, \& Green, 2012), family (e.g., parental supervision, family cohesion: Bacchini, Miranda, \& Affuso, 2011; Hamama \& Arazi, 2012), and community-level factors (e.g., exposure to community violence: McMahon, Felix, Halpert, \& Petropoulos, 2009).

In South Africa, adolescents in low-income Black communities have been identified as being at risk of both violence perpetration and victimization (Kaminer, du Plessis, Hardy, \& Benjamin, 2013). These communities were created as part of the apartheid-era Group Areas 
Act in terms of which Black South Africans were forcibly relocated to under-developed parts of the country that continue to be characterized by high levels of poverty, unemployment, gang violence, and substance abuse. Apartheid-era policies such as the migrant labour system also led to the fragmentation of traditional family structures and social networks that facilitate the supervision of children, leaving many vulnerable to victimization (Budlender \& Lund, 2011). It is probable that such socio-contextual factors explain the prevalence of aggressive behaviour among youth. However, they do not adequately account for variances in adolescent aggression or predict aggressive behaviour (Guerra, Huesmann, \& Spindler, 2003). In attempting to explain this variance, Huesmann and Guerra (1997), drawing on social learning theories, proposed that cognitive mechanisms are central in accounting for differences in the perpetration of aggressive behaviour. These authors proposed that cognitive scripts or schemas about the acceptability or unacceptability of aggressive behaviour mediate the relationship between predispositional factors and aggression. These cognitive scripts are acquired through observational learning from parents, peers, and other significant influences; identification processes; and personal evaluation (Guerra et al., 2003).

Based on this assumption, Huesmann and Guerra (1997) developed the Normative Beliefs about Aggression Scale (NOBAGS), a 20-item scale that measures beliefs about the acceptability of aggressive behaviours. The NOBAGS consists of two subscales, namely, General Beliefs subscale about the acceptability of aggressive behaviours and Retaliation Beliefs subscale that measure the acceptability of retaliatory aggressive behaviours in response to a provocation. According to Huesmann and Guerra (1997), varying the conditions of provocation (weak and strong), as well as gender, enables four additional subscales to be derived from the 12 items of the Retaliation Beliefs subscale, namely, Approval of Retaliation-Weak Provocation subscale, Approval of Retaliation- Strong Provocation subscale, Approval of Retaliation against Males subscale, and Approval of Retaliation against Females subscale. Sample items for each subscale are included in Appendix 1.

The NOBAGS was originally developed for use with children, but it has since been reliably used for adolescents (Nicol \& Fleming, 2010) and adults (Kjos, 2008). In addition to the United States, the scale has successfully been used in a variety of contexts (United Kingdom - Amjad \& Skinner, 2008; Archer, 2004; Singapore - Lim \& Ang, 2009; Pakistan - Amjad \& Wood, 2009; Australia - Nicol \& Fleming, 2010; Israel - Shechtman \& Basheer, 2005; Germany Krahé \& Möller, 2004).

With respect to subscales, the NOBAGS has been used in a variety of ways. Some studies (e.g., Teglasi \& Rothman, 2001) have utilized the total scale (Total Approval of Aggression), while others (e.g., Zelli, Dodge, Lochman, \& Laird, 1999) have only used the two subscales (Retaliation Beliefs and General Beliefs). In addition, several studies have used only the Retaliation Beliefs subscale (Bellmore, Witkow, Graham, \& Juvonen, 2005) or only the General Beliefs subscale (Archer, 2004). 
Despite the widespread use of the NOBAGS, only a few studies have analysed the factor structure of the scale. However, in several studies, the items were modified to focus on specific types of aggression, and in others, only a partial analysis was conducted. Archer (2004) reported two factors resulting from a principal components analysis of the General Beliefs subscale, namely, General Beliefs-Positive and General Beliefs-Negative. Werner and Nixon (2004) subjected the two sub-scales of the NOBAGS (which was revised to include relational aggression) to separate factor analyses. The revised Retaliation subscale yielded four factors which were labelled as follows: relational aggressive retaliation, verbal aggression retaliation, rumour spreading retaliation, and physical aggression retaliation. The General Beliefs subscale produced three factors, but due to their similarity, two of the factors were combined by the authors. The resulting two factors were labelled as acceptability of physical aggression and acceptability of relational aggression. Amjad (2007) extracted three factors from the 20 items, the general beliefs factor as well as two factors based on appropriateness of aggressive response which were labelled Excessive Retaliation Beliefs (acceptability of retaliating in excess of the provocation) and Equal Retaliation Beliefs (acceptability of retaliation that matches the provocation). Nicol and Fleming (2010) conducted a factor analysis of the NOBAGS where items were modified to reflect mobile phone bullying and deleted seven items that cross-loaded. The remaining 13 items loaded on two factors, namely, Retaliatory Beliefs and General Beliefs.

While Huesmann and Guerra (1997) suggested that the NOBAGS has several subscales, they did not actually test whether these subscales are distinct constructs. A full analysis of the factor structure of the NOBAGS has as such not yet been conducted. This study, therefore, presents the first full test of the factor structure of the NOBAGS.

There is no indication that the NOBAGS has been used in published research in South Africa. Several researchers (Milfont \& Fischer, 2010) have emphasized that cross-cultural studies investigating child and adolescent problem behaviours tend to assume that measures developed with one group equally assesses constructs across cultural groups. However, a measure developed for a given construct (e.g., beliefs about aggressive behaviour) in one particular group may not assess the same construct in the same manner in other groups owing to conceptual, structural, or metric differences (Byrne \& Van de Vijver, 2010). As such, it is problematic to assume universality of meaning across groups and that observed differences are a reflection of actual differences rather than different patterns of responses to items of a specific measure. For this reason, demonstrating the factor structure and equivalence of constructs and measures is considered a prerequisite for accurate and meaningful comparisons across diverse cultural groups (Harachi, Choi, Abbott, Catalano, \& Bliesner, 2006; Kankaraš \& Moors, 2010; Tran, Ngo, \& Conway, 2003).

The purpose of this study was to examine the psychometric properties of the scale when used in this country. In particular, the study examines the normative data, reliability, and factor structure of the NOBAGS. With regard to factor structure, this study examines the various models proposed in the literature, namely, (1) a total scale of approval of aggression, (2) a total approval of aggression scale as well as two subscales (General and Retaliation 
subscales), (3) only two subscales (General and Retaliation subscales), (4) a retaliation subscale divided by gender, and (5) a retaliation sub-scale divided by provocation strength.

\section{Method}

A cross-sectional survey design was used for the study.

\section{Participants}

Participants were 229 pupils enrolled in four different secondary schools located in lowincome settings in the Mitchells Plain area of Cape Town, South Africa. Mitchells Plain was created by the Apartheid government in the early 1970 s as a township for one part of the Black population in terms of the official policy of segregation. Today, it is one of South Africa's largest townships, and major parts of Mitchells Plain have deteriorated into urban ghettos characterized by high levels of poverty, unemployment, gang violence, and substance addiction among youth (Gebhardt, 2013).

The majority of participants in this study were female (61.1\%) and in Grade 10 (47.6\%). The age of the participants ranged from 13 to 19 years $(M=15.68$, standard deviation $[S D]=1.22)$ and household size of participants ranged between 1 and $25(M=5.49, S D=2.61)$.

\section{Instrument}

The NOBAGS (Huesmann \& Guerra, 1997) consists of 20 items designed to measure beliefs about the appropriateness of behaving aggressively. Twelve items measure the perception of how acceptable it is to behave aggressively under various conditions of provocation (termed retaliation beliefs), while eight items measure general beliefs about the appropriateness of aggression when no conditions are specified (termed general beliefs about aggression).

All items are scored on a 4-point scale in such a way that '4' is the most approving of aggression and ' 1 ' is the least approving of aggression. The authors (Huesmann \& Guerra, 1997) found the NOBAGS to be a reliable and valid measure of normative beliefs about aggression. In particular, they report reliability coefficients ranging between .65 and .90 for the various subscales and found that normative beliefs about aggression correlate significantly with actual aggressive behaviour, especially for boys.

\section{Procedure}

The NOBAGS and a demographic questionnaire were distributed to participants after the last class of the day with instructions regarding the completion of the questionnaire. Participants completed the questionnaire in their classroom. There was a $70 \%$ response rate.

\section{Ethical considerations}

Ethical approval for the study was obtained from the University of the Western Cape through the Psychology Department and from the South African Department of Education. Informed consent was also obtained at the school level from school principals and consent forms were sent to all primary caregivers of learners. Learners whose parents consented for them to 
participate in the study were provided with information about the research project during one of their regular classes and asked to assent if they wanted to participate. Those learners who assented were included in the study.

\section{Data analysis}

Data were subsequently captured using the Statistical Package for the Social Sciences (SPSS 24). Descriptive statistics were subsequently generated and a confirmatory factor analysis was conducted.

\section{Results}

The mean values, $S D$ s, and reliabilities (coefficient alpha) for the total scale, as well as for the various subscales, are reported in Table 1, together with the mean values and SDs reported by Huesmann, Guerra, Miller, and Zelli (2011) for a sample of 1550 North American elementary school children.

The mean values and SDs obtained in this study are very similar to those reported by Huesmann et al. (2011) with the exception of the strong provocation subscale where the difference between the two samples was 0.40. Apart from the weak provocation subscale, the general trend is that the mean values obtained in this study are slightly lower.

Table I. Descriptive statistics and reliabilities for the NOBAGS scale.

\begin{tabular}{|c|c|c|c|c|c|c|}
\hline & \multicolumn{3}{|c|}{ This study } & \multicolumn{3}{|c|}{ Huesmann et al. (20II) } \\
\hline & $\alpha$ & Mean & $S D$ & $\alpha$ & Mean & $S D$ \\
\hline Total Approval of Aggression & .84 & 1.81 & 0.44 & .86 & 1.92 & 0.55 \\
\hline General Approval of Aggression & .81 & 1.45 & 0.48 & .80 & 1.50 & 0.55 \\
\hline Approval of Retaliation & .81 & 2.04 & 0.55 & .82 & 2.16 & 0.57 \\
\hline Approval of Retaliation-Weak Provocation & .77 & 1.96 & 0.58 & .75 & 1.94 & 0.62 \\
\hline Approval of Retaliation-Strong Provocation & .65 & 2.20 & 0.71 & .71 & 2.60 & 0.74 \\
\hline Approval of Retaliation against Males & .71 & 2.26 & 0.66 & .70 & 2.32 & 0.66 \\
\hline Approval of Retaliation against Females & .65 & $\mathrm{I} .83$ & 0.53 & .69 & 2.00 & 0.55 \\
\hline
\end{tabular}

NOBAGS: Normative Beliefs about Aggression Scale; SD: standard deviation.

The estimates of reliability (coefficient alpha) ranged between .65 and .84 , suggesting that the NOBAGS and the various subscales have acceptable levels of internal consistency in this sample. Similar to Huesmann et al. (2011), it was found that the Total Approval Scale had the highest level of internal consistency $(\alpha=.84)$, while the Approval of Retaliation against Females had the lowest reliability $(\alpha=.65)$.

With regard to the factor structure of the NOBAGS, Huesmann et al. (2011) indicate that normative beliefs about aggression may be represented by a total approval scale as well as two subscales, a general beliefs subscale and a retaliation beliefs subscale. To examine the factor structure of the NOBAGS, confirmatory factor analysis (CFA) was conducted to test three 
different models: a one general factor model (Total Approval of Aggression); a two-factor correlated model consisting of the proposed two subscales, General Approval and Approval of Retaliation; and a bi-factor model (Total approval of Aggression as well as two subscales, General Approval and Approval of Retaliation). The bi-factor model is similar to the model used by Heppner, Pretorius, Wei, Lee, and Wang (2002) and Tracey and colleagues (Tracey, Glidden, \& Kokotovic, 1988; Tracey \& Kokotovic, 1989). In CFA, the items of the scale are regarded as the observed measurements, while the hypothesized factors are regarded as the latent variables represented by the items (Bentler, 1995).

It is recommended that the items of the scale be grouped into parcels or bundles so as to avoid having to estimate a large number of parameters (Russel, Kahn, Spoth, \& Altmaier, 1998) and to reduce the possibility of distortion from idiosyncratic characteristics of individual items in fitting the model to the data (Heppner et al., 2002). It has been demonstrated that the creation of bundles allows for a distribution closer to normal (Takahashi \& Nasser, 1996) and it has also been empirically shown that the structural parameters (i.e., path coefficients) for bundled and individual items were largely the same (Russel et al., 1998). Given the 20-item scale, it was possible to construct five bundles of four items each. The one general factor, the two-factor correlated model, and the bi-factor model are shown in Figure 1. The one general factor model presumes that a single factor (Total Approval of Aggression) is the best representation of the factor structure of the NOBAGS. The two-factor correlated model indicates that the factor structure of the NOBAGS is best represented by two correlated subscales (General Approval and Approval of Retaliation), while the bi-factor model presumes that a total score (Total Approval of Aggression) as well as two subscales (General Approval and Approval of Retaliation) is the best representation of the factor structure.

The extent to which the hypothesized model fits the observed data is measured by the chisquare statistic $\left(\chi^{2}\right)$, where a non-significant $\chi^{2}$ is indicative of a good fit. Jöreskog (1969), however, pointed out that the $\chi^{2}$ test is very sensitive to sample size and also to violations of distributional assumptions. Some of the alternative indices proposed to assess goodness-of-fit include the following: goodness-of-fit index (GFI: best if close to .95 or greater), relative fit index (RFI: best if close to .95 or greater), normed fit index (NFI: best if close to .95 or greater), and root mean square error of approximation (RMSEA: best if close to .05 or less) (Byrne, 1994; Hu \& Bentler, 1999; Schumacker \& Lomax, 2004). In addition, Arbuckle (2012) suggests the inclusion of fit indices, such as Akaike's information criterion (AIC), which is used specifically for model comparisons. In general, lower levels of AIC are associated with better model fit. These indices are reported in Table 2. 


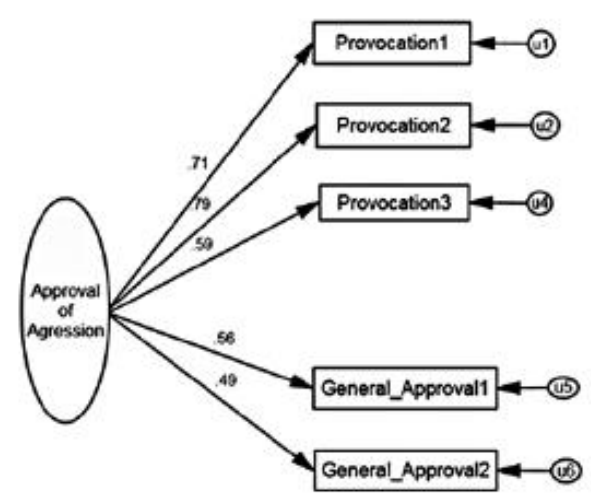

Model 1: One factor model

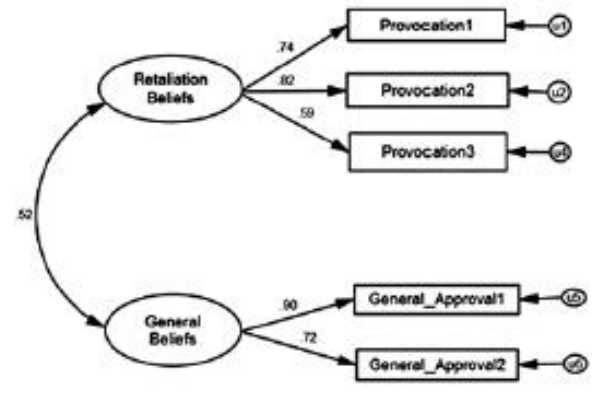

Model 2: Two correlated factor model

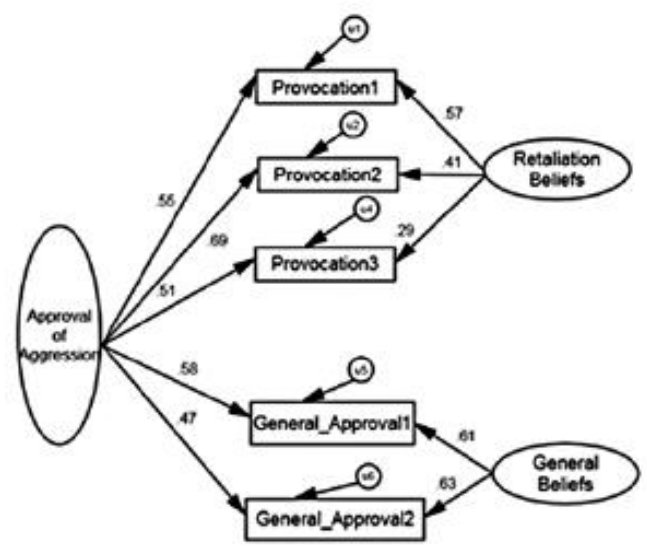

Model 3: Bi-factor model

Figure I. One-factor, two-factor, and bi-factor models of NOBAGS. Rectangles are observed variables (bundled items), ellipses are latent constructs, and small circles are residual variances.

Table 2 indicates that the one-factor model does not fit the data to an acceptable degree and represented the worst fit of the three models. The two-factor and bi-factor models, on the other hand, demonstrated a better fit with all the fit indices at acceptable levels. Comparing the two-factor and the bi-factor model, the model comparison index, namely, AIC, indicates that the two-factor model ( $\mathrm{AIC}=25.75$ ) is a marginally better model than the bi-factor model (AIC= 28.51). The bi-factor model would be consistent with the author's (Huesmann \& Guerra, 1997) original conceptualization of the NOBAGS as consisting of a total scale (Total Approval of Aggression) and two subscales (Retaliation Approval and General Approval of Aggression). 
Table 2. Fit indices for three models of the structure of the NOBAGS.

\begin{tabular}{|c|c|c|c|c|}
\hline Goodness of fit indices & Best fit indicator & One-factor model & Two-factor model & $\mathrm{Bi}$-factor model \\
\hline$\chi^{2}$ & & 88.84 & 4.05 & 2.51 \\
\hline$p$-value & Non-significant & $<.001$ & ns & ns \\
\hline GFI & $>.95$ & .87 & .99 & .99 \\
\hline RFI & $>.95$ & .49 & .97 & .96 \\
\hline $\mathrm{NFI}$ & $>.95$ & .75 & 99 & .99 \\
\hline RMSEA & $<.05$ & .27 & .01 & .03 \\
\hline $\mathrm{AIC}$ & Lower levels & 108.84 & 25.75 & 28.51 \\
\hline
\end{tabular}

$\chi^{2}$ : chi-square; GFI: goodness-of-fit index; RFI: relative fit index; NFI: normed fit index; RMSEA: root mean square error of approximation; AIC: Akaike's information criterion; NOBAGS: Normative Beliefs about Aggression Scale.

The subscales which are presumed to derive from the Retaliation Beliefs subscale (provocation type and gender) were also tested with CFA. Given the number of items that are presumed to represent the various subscales, the number of items in each bundle varied as follows: Approval of Retaliation-Weak Provocation: 2 bundles $\times 4$ items, Approval of Retaliation-Strong Provocation: 2 bundles $\times 2$ items, Approval of Retaliation against Males: 2 bundles $\times 3$ items, and Approval of Retaliation against Females: 2 bundles $\times 3$ items. The models that were tested are shown in Figure 2. The results of the CFA for the models in Figure 2 are shown in Table 3. The fit indices for the two models show that both models fit the data to an acceptable degree. In the case of Retaliation Beliefs related to gender, at least three of the indices demonstrate a good fit (GFI, RFI, and NFI >0.95), while in the case of the Retaliation Beliefs related to provocation type (weak and strong), all five fit indices reflect a good fit ( $\chi^{2}>$ 0.05; GFI, RFI, and NFI >0.95; and RMSEA <0.05). The AIC index reflects that the provocation-type model $(\mathrm{AIC}=36.62)$ is a slightly better model than the gender model.

In summary, the results of the CFA provide empirical support for the use of the NOBAGS as a bi-factor scale (the total scale together with two subscales) or a two-factor scale (the two subscales alone) in respect of Black adolescents in South Africa. In addition, CFA also indicates that there is support for conceptualizing the Retaliation Beliefs subscale as either beliefs related to gender or beliefs related to provocation type.

\section{Discussion}

Research in South Africa requires instruments that are sensitive to culture and context. Psychological research in this country usually involves comparisons between people exposed to different social, political, and historical factors. This type of research necessitates instruments capable of identifying similar psychological constructs in groups that differ. This study aimed to examine the psychometric properties of the NOBAGS. Although this scale has been extensively used in research focusing on child and adolescent aggression, information is lacking on its psychometric properties, in particular the factor structure of the instrument. This study confirmed the generalizability of the NOBAGS as used with a sample of adolescents from low-income communities in South Africa. In particular, it confirms that 
the NOBAGS is a reliable instrument in this context and demonstrates the factor structure of the scale. The results of CFA indicate the suitability of using the NOBAGS as a two-factor scale, as a scale consisting of a total factor as well as two subscales, using the provocationtype factors and the gender-based retaliation factors.

The NOBAGS has proven to be highly adaptable, with the scale having been modified for a variety of purposes. Nicol and Fleming (2010) changed the phrasing of some items to reflect mobile phone bullying and reduced the scale to 13 items. Werner and Nixon (2005) as well as Krahé and Möller (2004) modified the NOBAGS to include a focus on relational aggression in addition to verbal and physical aggression.

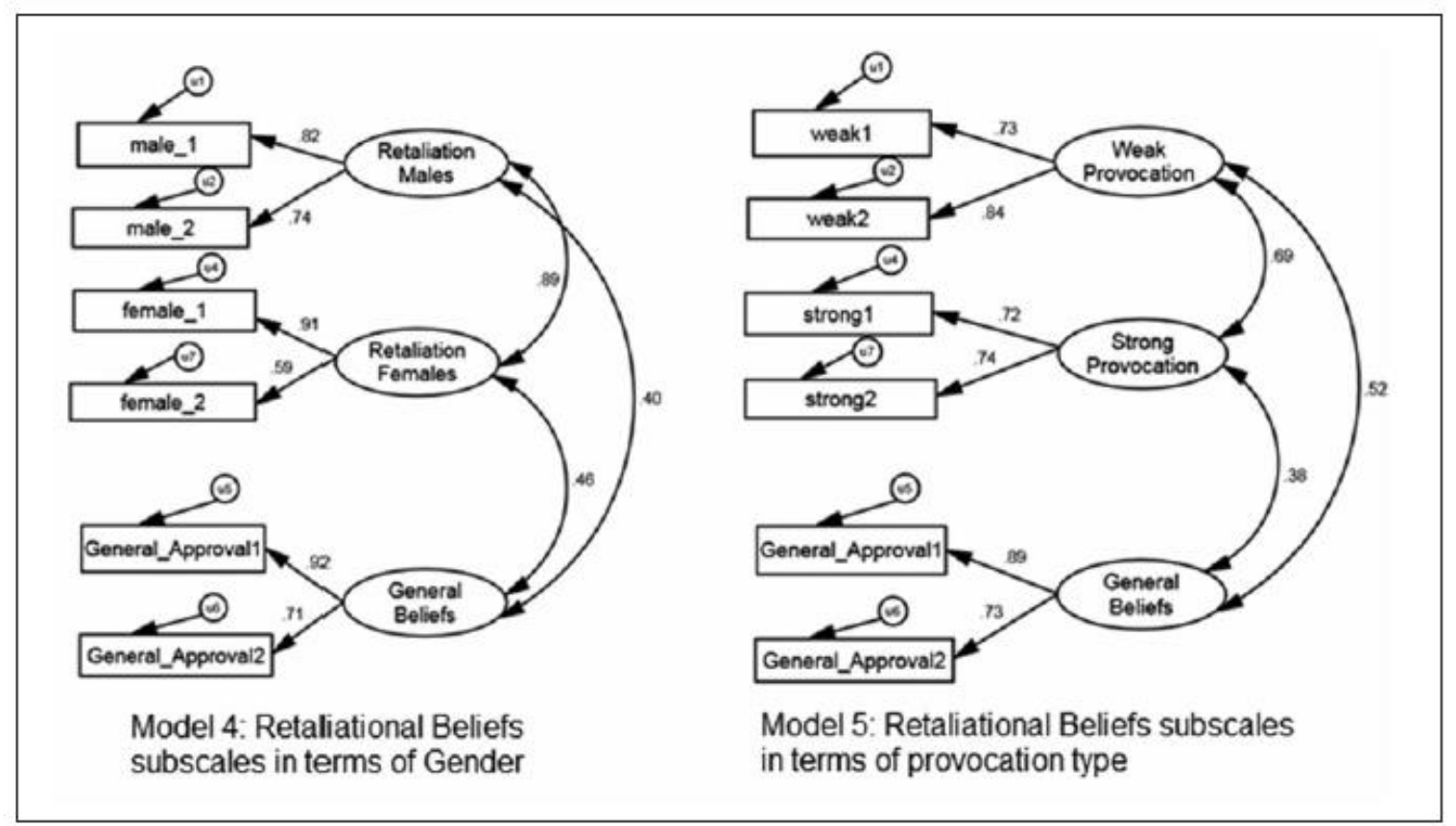

Figure 2. Models of Retaliation Beliefs subscales in terms of gender and provocation type. Rectangles are observed variables (bundled items), ellipses are latent constructs, and small circles are residual variances.

Table 3. Fit indices for two models of the structure of the Retaliation Scale of the NOBAGS.

\begin{tabular}{llcc}
\hline Goodness-of-fit indices & Best fit indicator & Gender model & Provocation-type model \\
\hline$\chi^{2}$ & & 16.67 & 4.05 \\
p-value & Non-significant & $<.05$ & $\mathrm{~ns}$ \\
GFI & $>.95$ & .98 & .99 \\
RFI & $>.95$ & .92 & .96 \\
NFI & $>.95$ & .97 & .99 \\
RMSEA & $<.05$ & .09 & .02 \\
AIC & Lower levels & 46.67 & 36.62 \\
\hline
\end{tabular}

$\chi^{2}$ : chi-square; GFI: goodness-of-fit index; RFI: relative fit index; NFI: normed fit index; RMSEA: root mean square error of approximation; AIC: Akaike's information criterion; NOBAGS: Normative Beliefs about Aggression Scale. 
Shechtman and Basheer (2005) focused on inter-group relations and revised the NOBAGS items to include provocations within and between ethnic groups. Furthermore, using different groupings of items in the Retaliation Beliefs sub-scale, several variations of the NOBAGS have been reported. Lim and Ang (2009), for example, used the scale as a three-factor scale, namely, general beliefs, and acceptability of retaliatory behaviour towards males and females, respectively. Similarly, Werner and Nixon (2004) as well as Kjos (2008) focused on beliefs about forms of aggression and categorized the retaliation items of the NOBAGS as either verbal aggression or physical aggression, while Krahé and Möller (2004) distinguished between physical aggression and relational aggression.

This adaptability of the NOBAGS is particularly relevant for the South African context. It means that the instrument can, for example, be adapted to assess beliefs regarding the acceptability of different forms of aggressive behaviour that are prevalent in the country (e.g., rape, intimate partner violence). This type of research could in turn inform intervention efforts. Werner and Nixon (2005) have emphasized that many intervention strategies are limited in their effectiveness owing to their focus on addressing general beliefs about the acceptability of aggressive behaviour. Instead, targeting specific beliefs about the acceptability of certain forms of aggression (e.g., approval of aggression against women) is more effective in producing lasting behavioural change (Guerra, Henry, Huesmann, \& Tolan, 2007).

In South Africa, existing intervention programmes aimed at addressing aggressive behaviour among adolescents have focused on enhancing conflict resolution skills, addressing problematic constructions of gender that endorse violence, and strengthening relationships with caregivers. Various school- and community-based interventions have also been developed (Mahlangu, Gevers, \& De Lannoy, 2014). Despite the importance of these strategies, the intersection between normative beliefs and predispositional factors in regulating aggressive behaviour means that targeting beliefs related to aggression is central to reducing the propensity to engage in aggressive acts. Having a reliable and valid measure of beliefs about aggression is therefore a prerequisite for effective intervention efforts.

Cross-cultural research on the NOBAGS not only provides useful psychometric information but also assists researchers in understanding the link between normative beliefs about aggression and actual aggressive behaviour in the South African context. Various local studies have investigated the correlates of aggressive behaviour among adolescents and have identified family functioning (Bradford et al., 2004), problematic constructions of gender (Boonzaier \& de La Rey, 2003), substance abuse (Plüddemann, Flisher, McKetin, Parry, \& Lombard, 2010), community violence (Shields, Nadasen, \& Pierce, 2008), and exposure to trauma (Kaminer et al., 2013) as positively correlated with aggression. However, no published South African research has focused on the role of cognitive scripts in aggressive behaviour. Given the consistent finding that normative beliefs predict aggression and mediate the relationship between risk factors and aggression (Nicol \& Fleming, 2010; Werner \& Nixon, 2005), this type of research is of particular relevance to the South African context. 
In sum, this study has both theoretical and practical implications for researchers and mental health care professionals working to understand and address aggressive behaviour.

The study does have certain limitations. First, participants were high school students in low-income communities and it is therefore uncertain whether the findings of the study generalize to other populations or other age groups. Future studies need to investigate the replicability of the NOBAGS structure with different samples, especially given the .65 alpha coefficient found for the Approval of Retaliation-Strong Provocation and Approval of Retaliation against Females sub-scales. Second, this study largely focused on the factor structure of the NOBAGS, and further validity studies are needed to examine the extent to which the scale actually measures normative beliefs about aggression.

\section{Conclusion}

The findings of the study extend previous research by providing the first information, to the author's knowledge, about the psychometric properties of the instrument for a sample of South African adolescents. The results show that normative beliefs about aggression do not exist as a single psychological construct, but as a multidimensional construct. This study provides the foundation for future research investigating the correlates of beliefs about aggression as well as the relationship between beliefs and aggressive behaviour. The appropriateness of the scale for different populations (e.g., adults) in South Africa is also an important focus for future studies.

\section{Funding}

This work was financially supported by the National Research Foundation (NRF) of South Africa.

\section{Note}

1. The Normative Beliefs about Aggression Scale (NOBAGS) is copyright protected, and permission to use the 20-item instrument can be obtained from the developers, Huesmann and Guerra (1997). 


\section{References}

Amjad, N. (2007). Role of moral beliefs in aggression - An investigation across two cultures (Unpublished $\mathrm{PhD}$ dissertation). University of Warwick, UK. Retrieved from http://go.warwick.ac.uk/wrap/2341

Amjad, N., \& Skinner, M. (2008). Normative beliefs about aggression and retaliation: Association with aggressive behaviour and anticipatory self-censure. Journal of Behavioural Sciences, 18, 53-73.

Amjad, N., \& Wood, A. M. (2009). Identifying and changing the normative beliefs about aggression which lead young Muslim adults to join extremist anti-Semitic groups in Pakistan. Aggressive Behavior, 35, 514-519.

Arbuckle, J. L. (2012). Amos 21.o User's Guide. Chicago, IL: SPSS Inc.

Archer, J. (2004). Which attitudinal measures predict trait aggression? Personality and Individual Differences, 36, 47-60.

Bacchini, D., Miranda, M. C., \& Affuso, G. (2011). Effects of parental monitoring and exposure to community violence on antisocial behavior and anxiety/depression among adolescents. Journal of Interpersonal Violence, 26, 269-292.

Bellmore, A. D., Witkow, M. R., Graham, S., \& Juvonen, J. (2005). From beliefs to behavior: The mediating role of hostile response selection in predicting aggression. Aggressive Behavior, 31, 453-472.

Bentler, P. M. (1995). EQS: Structural equations program manual. Encino, CA: Multivariate Software. Boonzaier, F., \& de La Rey, C. (2003). 'He's a Man, and I'm a woman' cultural constructions of masculinity and femininity in South African women's narratives of violence. Violence against Women, 9, 1003-1029.

Boyes, M. E., Bowes, L., Cluver, L. D., Ward, C. L., \& Badcock, N. A. (2014). Bullying victimisation, internalising symptoms, and conduct problems in South African children and adolescents: A longitudinal investigation. Journal of Abnormal Child Psychology, 42, 1313-1324.

Bradford, K., Barber, B. K., Olsen, J. A., Maughan, S. L., Erickson, L. D., Ward, D., . . Stolz, H. E. (2004). A multi-national study of interparental conflict, parenting, and adolescent functioning: South Africa, Bangladesh, China, India, Bosnia, Germany, Palestine, Colombia, and the United States. Marriage \& Family Review, 35(3-4), 107-137.

Budlender, D., \& Lund, F. (2011). South Africa: A legacy of family disruption. Development and Change, 42, 925-946.

Byrne, B. M. (1994). Structural equation modeling with EQS and EQS/Windows. Thousand Oaks, CA: SAGE. Byrne, B. M., \& Van de Vijver, F. J. (2010). Testing for measurement and structural equivalence in large-scale cross-cultural studies: Addressing the issue of nonequivalence. International Journal of Testing, 10, 107-132.

Gebhardt, M. (2013, September 20). Mitchells Plain worst area for crime in SA. Business Day. Retrieved from https://www.businesslive.co.za/bd/national/2013-09-20-mitchellsplain-worst-area-for-crime-in-sa/

Guerra, N. G., Henry, D., Huesmann, L. R., \& Tolan, P. (2007). Changing the way children 'think' about aggression. Journal of Consulting and Clinical Psychology, 75, 160-167. 
Guerra, N. G., Huesmann, L. R., \& Spindler, A. (2003). Community violence exposure, social cognition, and aggression among urban elementary school children. Child Development, 74, 1561-1576.

Hamama, L., \& Arazi, Y. (2012). Aggressive behaviour in at-risk children: Contribution of subjective well-being and family cohesion. Child \& Family Social Work, 17, 284-295.

Harachi, T. W., Choi, Y., Abbott, R. D., Catalano, R. F., \& Bliesner, S. L. (2006). Examining equivalence of concepts and measures in diverse samples. Prevention Science, 7, 359368.

Heppner, P. P., Pretorius, T. B., Wei, M., Lee, D., \& Wang, Y.-W (2002). Examining the generalizability of problem-solving appraisal in Black South Africans. Journal of Counseling Psychology, 49, 484-498.

Hu, L., \& Bentler, P. M. (1999). Cutoff criteria for fit indexes in covariance structure analysis: Conventional criteria versus new alternatives. Structural Equation Modeling, 6, 1-55.

Huesmann, L.R., Guerra, N.G., Miller, L., \& Zelli, A. (2011). The Normative Beliefs about Aggression Scale [NOBAGS]. Retrieved from www.rcgd.isr.umich.edu/aggr/Measures/NormativeBeliefs

AboutAggScale.2011.pdf

Huesmann, L. R., \& Guerra, N. G. (1997). Children's normative beliefs about aggression and aggressive behavior. Journal of Personality and Social Psychology, 72, 408-419.

Jewkes, R., Flood, M., \& Lang, J. (2015). From work with men and boys to changes of social norms and reduction of inequities in gender relations: A conceptual shift in prevention of violence against women and girls. The Lancet, 385, 1580-1589.

Jöreskog, K. G. (1969). A general approach to confirmatory factor analysis. Psychometrika, 34, 183-202.

Kaminer, D., du Plessis, B., Hardy, A., \& Benjamin, A. (2013). Exposure to violence across multiple sites among young South African adolescents. Peace and Conflict: Journal of Peace Psychology, 19, 112-124. Kankaraš, M., \& Moors, G. (2010). Researching measurement equivalence in cross-cultural studies. Psihologija, 43, 121-136.

Kjos, A. A. (2008). Adults who play violent video games and their Normative Beliefs about Aggression (Master's thesis). Pacific University. Retrieved from http://commons.pacificu.edu/spp/50

Krahé, B., \& Möller, I. (2004). Playing violent electronic games, hostile attributional style and aggression-related norms in German adolescents. Journal of Adolescence, 27, $53-69$.

Liang, H., Flisher, A. J., \& Lombard, C. J. (2007). Bullying, violence, and risk behavior in South African school students. Child Abuse \& Neglect, 31, 161-171.

Lim, S. H., \& Ang, R. P. (2009). Relationship between boys' normative beliefs about aggression and their physical, verbal and indirect aggressive behaviours. Adolescence, $44,635-650$.

Mahlangu, P., Gevers, A., \& De Lannoy, A. (2014). Adolescents: Preventing interpersonal and gender-based violence. In S Mathews, L Jamieson, L Lake, \& C Smith (Eds.), South African Child Gauge (pp. 73-79). Children's Institute, University of Cape Town: Cape Town, South Africa. 
McMahon, S. D., Felix, E. D., Halpert, J. A., \& Petropoulos, L. A. (2009). Community violence exposure and aggression among urban adolescents: Testing a cognitive mediator model. Journal of Community Psychology, 37, 895-910.

Milfont, T. L., \& Fischer, R. (2010). Testing measurement invariance across groups: Applications in crosscultural research. International Journal of Psychological Research, 3, 111-121.

Nicol, A., \& Fleming, M. J. (2010). 'i h8 u': The influence of normative beliefs and hostile response selection in predicting adolecsents'mobile phone bullying. Journal of School Violence, 9, 212-231.

Plüddemann, A., Flisher, A. J., McKetin, R., Parry, C., \& Lombard, C. (2010). Methamphetamine use, aggressive behavior and other mental health issues among high-school students in Cape Town, South Africa. Drug and Alcohol Dependence, 109, 14-19.

Russel, D. W., Kahn, J. H., Spoth, R., \& Altmaier, E. M. (1998). Analyzing data from experimental studies: A latent variable structural equation modeling approach. Journal of Counseling Psychology, 45, 18-29.

Russell, M., Cupp, P. K., Jewkes, R. K., Gevers, A., Mathews, C., LeFleur-Bellerose, C., . . . Small, J. (2014). Intimate partner violence among adolescents in Cape Town, South Africa. Prevention Science, 15, 283-295.

Schumacker, R. E., \& Lomax, R. G. (2004). A beginner's guide to structural equation modeling (2nd ed.). Mahwah, NJ: Lawrence Erlbaum.

Shechtman, Z., \& Basheer, O. (2005). Normative Beliefs supporting aggression of Arab children in an inter-group conflict. Aggressive Behavior, 31, 324-335.

Shields, N., Nadasen, K., \& Pierce, L. (2008). The effects of community violence on children in Cape Town, South Africa. Child Abuse \& Neglect, 32, 589-601.

Swart, L. A., Seedat, M., \& Nel, J. (2015). Alcohol consumption in adolescent homicide victims in the city of Johannesburg, South Africa. Addiction, 110, 595-601.

Takahashi, T., \& Nasser, F. (1996, April 8-12). The impact of using item parcels on ad hoc Goodness of Fit Indices in confirmatory factor analysis: An empirical example. Paper presented at the Annual Meeting of the American Educational Research Association, New York, NY.

Teglasi, H., \& Rothman, L. (2001). STORIES - A classroom based program to reduce aggressive behavior. Journal of School Psychology, 39, 71-94.

Tracey, T. J., Glidden, C. E., \& Kokotovic, A. M. (1988). Factor structure of the counsellor rating form. Journal of Counseling Psychology, 35, 330-335.

Tracey, T. J., \& Kokotovic, A. M. (1989). Factor structure of the working alliance inventory. Journal of Consulting and Clinical Psychology, 1, 207-210.

Tran, T. V., Ngo, D., \& Conway, K. (2003). A cross-cultural measure of depressive symptoms among Vietnamese Americans. Social Work Research, 27, 56-64.

Wallace, M. T., Barry, C. T., Zeigler-Hill, V., \& Green, B. A. (2012). Locus of control as a contributing factor in the relation between self-perception and adolescent aggression. Aggressive Behavior, 38, 213-221.

Werner, N. E., Hill, L. G., \& Nixon, C. (2004). An exploration of the social-cognitive bases of relational aggression: Age, sex, and ethnic differences in relations between 
normative beliefs about aggression and aggressive behavior. Paper presented at Aggression Workshop, Berlin, Germany. Downloaded from: http://www.aggressionsworkshop.de/2003/doc/abs_4.pdf

Werner, N. E., \& Nixon, C. L. (2005). Normative beliefs and relational aggression: An investigation of the cognitive bases of adolescent aggressive behaviour. Journal of Youth and Adolescence, 34, 229-243.

Zelli, A., Dodge, K. A., Lochman, J. E., \& Laird, J. (1999). The distinction between beliefs legitimising aggression and deviant processing of social cues: Testing measurement validity and the hypothesis that biased processing mediates the effects of beliefs on aggression. Journal of Personality and Social Psychology, 77, 150-166.

\section{Appendix 1}

Sample items from the Normative Beliefs about Aggression Scale (NOBAGS) ${ }^{1}$

General Beliefs subscale

1. In general, it is wrong to hit other people.

2. If you're angry, it is OK to say mean things to other people.

3. In general, it is OK to yell at others and say bad things.

4. It is usually OK to push or shove other people around if you're mad.

\section{Retaliation Beliefs subscale}

1. Suppose a boy says something bad to another boy, John (Weak provocation) Do you think it's OK for John to scream at him?

2. Suppose a boy hits another boy, John (Strong provocation) Do you think it's wrong for John to hit him back?

3. Suppose a boy hits a girl

Do you think it's OK for the girl to hit him back? (Retaliation against males)

4. Suppose a girl hits a boy

Do you think it's wrong for the boy to hit her back? (Retaliation against females) 